Review

\title{
Formaldehyde Gas Sensors: A Review
}

\section{Po-Ren Chung ${ }^{1}$, Chun-Ta Tzeng ${ }^{1}$, Ming-Tsun Ke ${ }^{2 *}$ and Chia-Yen Lee ${ }^{3, *}$}

1 Department of Architecture, National Cheng Kung University, Tainan 701, Taiwan;

E-Mails: benjamin@archilife.ncku.edu.tw (P.-R.C.); ctmt@mail.ncku.edu.tw (C.-T.T.)

2

Department of Energy and Refrigerating Air-conditioning Engineering,

National Taipei University of Technology, Taipei 106, Taiwan

3 Department of Vehicle Engineering, National Pingtung University of Science and Technology, Pingtung 912, Taiwan

* Authors to whom correspondence should be addressed; E-Mails: leecy@ mail.npust.edu.tw (C.-Y.L.); mtke@ntut.edu.tw (M.-T.K.); Tel.: +886-8-770-3202 (ext. 7561) (C.-Y.L.);

Fax: +886-8-774-0552 (C.-Y.L.); Tel.: +886-2-2771-2171 (ext. 3509) (M.-T.K.);

Fax: +886-2-2731-4919 (M.-T.K.).

Received: 27 February 2013; in revised form: 25 March 2013 / Accepted: 26 March 2013 /

Published: 2 April 2013

\begin{abstract}
Many methods based on spectrophotometric, fluorometric, piezoresistive, amperometric or conductive measurements have been proposed for detecting the concentration of formaldehyde in air. However, conventional formaldehyde measurement systems are bulky and expensive and require the services of highly-trained operators. Accordingly, the emergence of sophisticated technologies in recent years has prompted the development of many microscale gaseous formaldehyde detection systems. Besides their compact size, such devices have many other advantages over their macroscale counterparts, including a real-time response, a more straightforward operation, lower power consumption, and the potential for low-cost batch production. This paper commences by providing a high level overview of the formaldehyde gas sensing field and then describes some of the more significant real-time sensors presented in the literature over the past 10 years or so.
\end{abstract}

Keywords: formaldehyde; gas sensor; indoor air; MEMS; sick building syndrome (SBS) 


\section{Origin and Measurement Technology of Formaldehyde in Air}

Formaldehyde is one of the volatile organic compounds (VOCs) that are widely used in household materials, which is associated with many health risk factors and has been identified as a major cause of sick building syndrome (SBS) [1-3]. SBS sufferers exhibit a range of symptoms which appear to be related to the time spent in a particular building [4]. The specific origins of SBS are not fully understood, but is thought that chemical and biological contaminants, and inadequate ventilation, all play a contributory role. Many of the upholstery, carpeting, wood and plastic products used in indoor environments emit VOCs, such as xylene and formaldehyde [5-13]. Consequently, the World Health Organization (WHO) has set a 30 min exposure limit of 0.08 ppm [14], while the US National Institute for Occupational Safety and Health (NIOSH) has established a maximum long-term exposure limit of 0.016 ppm (TWA) [15].

In the last two decades of the 20th century, a number of analytical methods for the determination of formaldehyde have been reported. These methods include spectrophotometry [16], gas chromatography (GC) [17], high-performance liquid chromatography [18], ion chromatography [19] and polarography [20]. Since these methods required expensive and bulky instrumentation with high power demand and well-trained operators, clearly, these procedures is unable to provide formaldehyde exposure information on a real-time basis.

To simplify the measurement of ambient formaldehyde, Hopkins et al. [21] proposed a GC-pulsed Helium Ionization Detector (pHID) apparatus aiming at formaldehyde detection and designed to operate at relatively high frequencies $\left(>10 \mathrm{~h}^{-1}\right)$. In order to maintain the simplicity of the apparatus, a back-flush system was used to prevent the build-up of water in the column and to increase the sample rate. However, the associated arrangements tend to be rather bulky and elaborate. With good selectivity and selectivity, miniaturized electrochemical sensors became available for detection of many different toxic gases in mid-1980s and were commercialized very soon. The sensors operate by reacting with the gas of interest and producing an electrical signal proportional to the gas concentration. However, the lifetime of an electrochemical sensor is highly dependent on the total amount of gas the sensor is exposed to during its lifetime, as well as other environmental conditions [22]. Over the past decade, emerging measurement technologies have contributed significantly to the miniaturization of measurement apparatus. As a result of advances in measurement technology, sensing instrumentation capable of accessing information at a real-time level is now available [10,22-48]. Reviewing the literature, it is found that the sensing mechanism of the majority of these sensors can be classified in as receptor-based or transducer-based formaldehyde sensors. The remainder of this paper presents a systematic review of the operational principles and advantages of each of the major formaldehyde gas sensors presented in the literature over the past 10 years or so.

In 1996, Vianello et al. [23] proposed a potentiometric formaldehyde detection system based on an aldehyde dehydrogenase ion-selective field effect transistor (ISFET, see Figure 1(a)). In the proposed approach, the atmospheric formaldehyde was dissolved in an aqueous solution and then deposited on the surface of an ISFET coated with the enzyme nicotinamide adenine dinucleoside (NAD). The formaldehyde concentration was then determined by measuring the change in the ISFET output signal during the subsequent reaction between the formaldehyde molecules and the enzyme. The experimental results showed that the sensor output voltage increased linearly with an increasing formaldehyde 
concentration (see Figure 1(b)). Moreover, it was shown that the minimum formaldehyde detection limit was around $0.1 \mathrm{ppm}$ and stability was long, up to several months.

Figure 1. (a) Schematic illustration of FET-based detection of gaseous formaldehyde. Left: general arrangement of sampling system. Right: Detailed view of FET sensor. (b) Potentiometric response of FET sensor given increasing formaldehyde concentration [23].

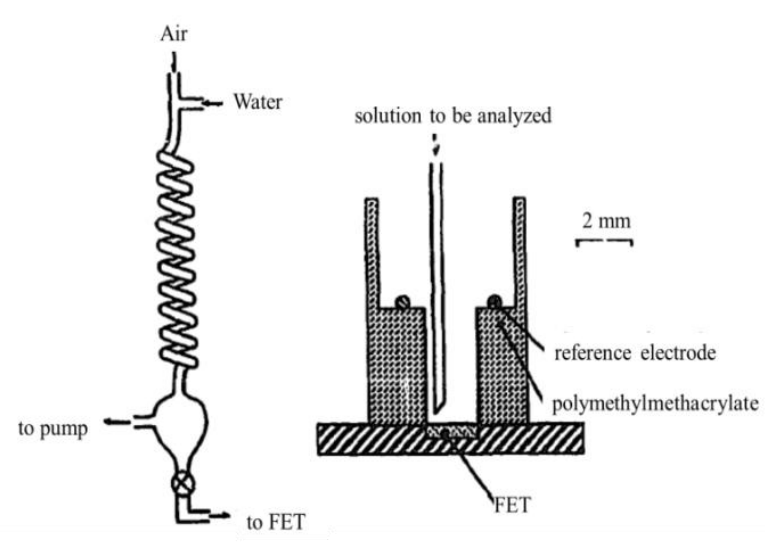

(a)

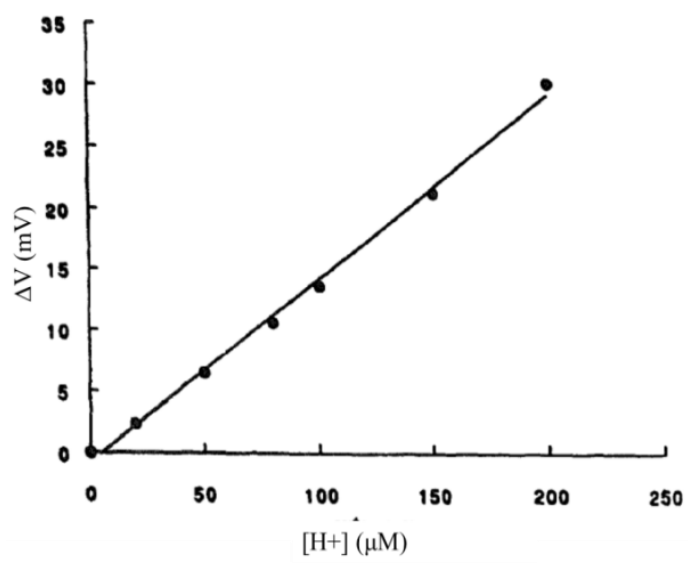

(b)

Sritharathikhun et al. [24] presented a method for determining trace amounts of formaldehyde in air by coupling a three-hole chromatomembrane cell (CMC) and a flow injection analysis (FIA) system. As shown in Figure 2(a), the CMC was used to collect and concentrate trace amounts of gaseous formaldehyde in water and the resulting solution was then introduced into the carrier stream of the FIA system.

Figure 2. (a) Schematic illustration of flow injection system coupled with collection/concentration system for formaldehyde determination. (RS, reagent solution; CS and AS, carrier and absorbing solutions, respectively; P1, double-plunger pump; P2, peristaltic pump; P3, syringe pump; V1 and V2, six-way valves; V3, three-way valve; S, sample; M, mixing joint; DG, degassing unit; RC, reaction coil; D, detector; $\mathrm{BPC}$, back-pressure coil; CMC, chromatomembrane cell; BPB, biporous PTFE block; PMF, porous membrane filter. (A) Introduction of absorbing solution into FIA system; (B) air sampling); (b) Variation of peak area and peak height with air sample volume [24].

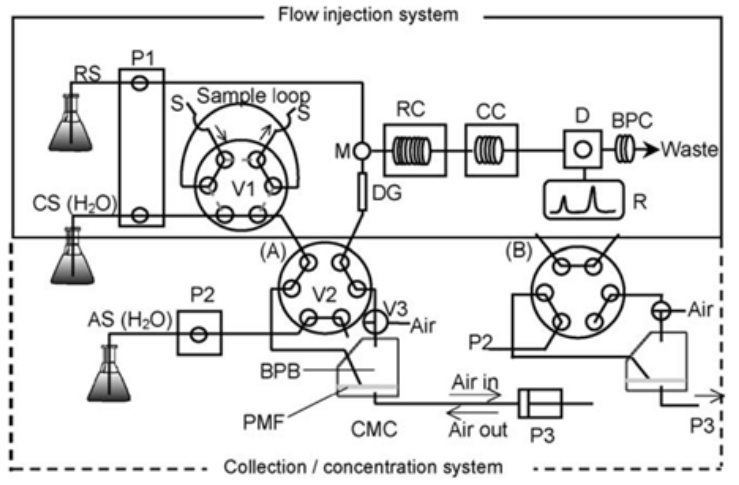

(a)

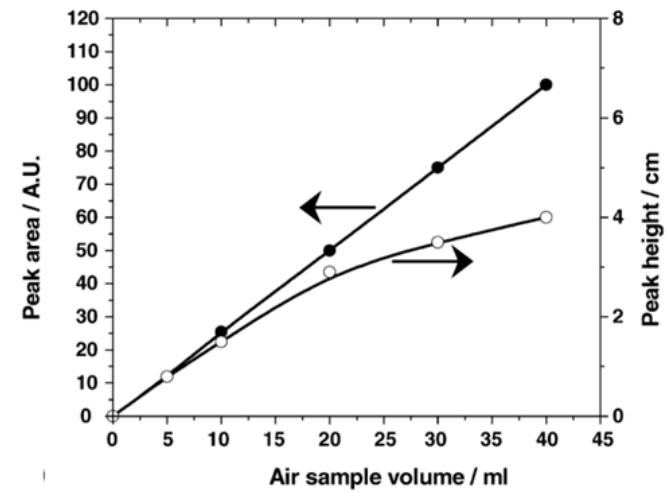

(b) 
Finally, the formaldehyde concentration was measured both spectrophotometrically and fluorometrically following a reaction between the solution and a mixed reagent of acetylacetone and ammonium acetate. The results obtained using an air flow rate of $6 \mathrm{~mL} \mathrm{~min} \operatorname{mon}^{-1}$ and a sample size of $20 \mathrm{~mL}$ showed that the formaldehyde concentration in indoor air was equal to around $5.14 \mathrm{ppb}$ (see Figure 2(b)). Vianello et al. [25] developed a system for the on-line detection of atmospheric formaldehyde comprising a wet scrubber, a micro-reactor containing immobilized formaldehyde dehydrogenase (FDH), and a conductometric transducer (see Figure 3(a)). In the proposed system, atmosphere was sampled by a constant flow gas sampler. Formaldehyde was measured sending the sampled atmosphere directly to the scrubbing coil by a switching valve (line 1). Blank signals were obtained by switching the sampled air through a HCHO trap containing 2,4-dinitrophenlhydrazine loaded filters (line 2). The HCHO stripping device was a glass coil. A 2-way peristaltic pump was used to control the solution flow rate. As shown in Figure 3(b), the system was capable of detecting formaldehyde concentrations of $0.05-2 \mathrm{ppm}$ with a sensitivity of $20 \mu \mathrm{S} / \mathrm{ppm}$. Though some devices were miniaturized quite a bit (e.g., the microreactor), the supporting system was still bulky and required to be reduced by some engineering tools.

Figure 3. (a) Schematic illustration of biosensor setup. Atmospheric air is sampled by constant flow gas sampler and formaldehyde concentration is measured by sending air sample directly to scrubbing coil via switching valve (line 1). Note that blank signals are obtained by switching sampled air through HCHO trap containing 2,4-dinitrophenylhydrazine-loaded filter (line2). (b) Variation of conductivity with formaldehyde concentration [25].

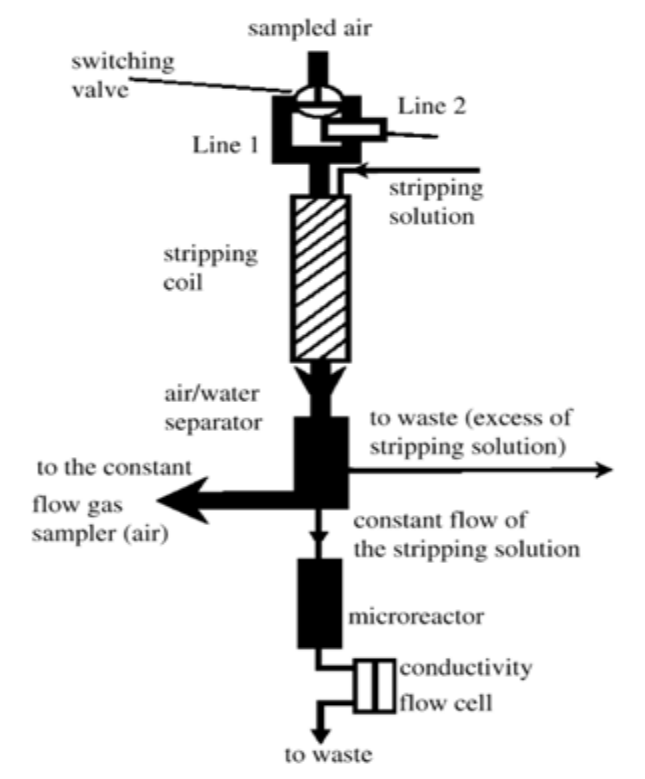

(a)

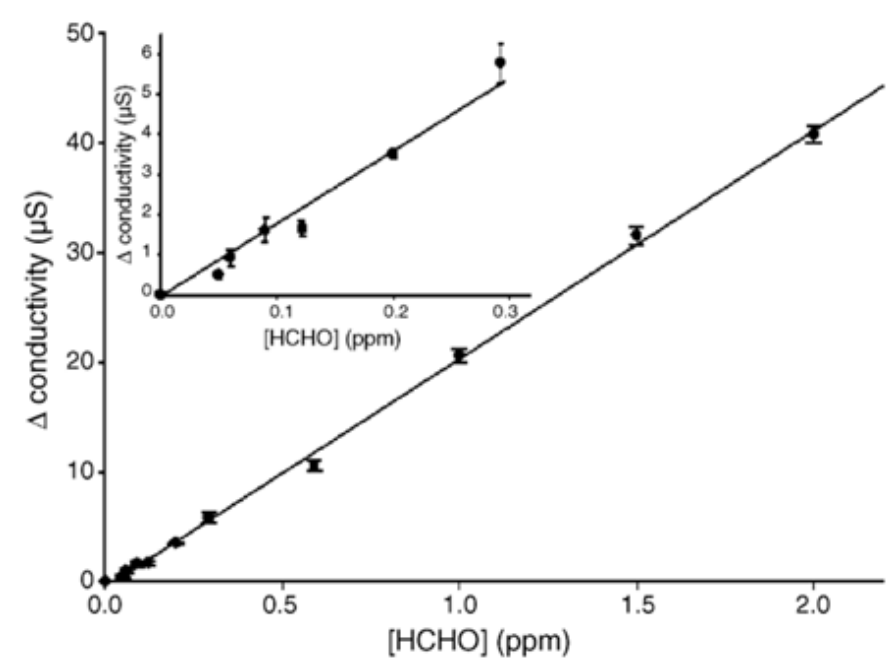

(b)

In general, the gaseous formaldehyde detection systems presented in [23-25] have a high sensitivity and a wide measurement range, but they are complex. As a result, their use is limited to a laboratory environment. In practice, however, a requirement exists for low-cost, portable real-time measurement systems such that the formaldehyde concentration can be measured in situ (i.e., without the need to collect samples and then transport them to a remote laboratory for testing purposes.) Accordingly, 
various small-scale formaldehyde measurement systems based on the use of sensing materials as receptors or transducers (Table 1) have been proposed in recent years [26].

Table 1. Performance of small-scale formaldehyde gas sensors.

\begin{tabular}{|c|c|c|c|c|c|}
\hline Year & Authors & $\begin{array}{c}\text { Functional } \\
\text { Principle }\end{array}$ & $\begin{array}{c}\text { Sensing Materials } \\
\text { Working Temperature }\end{array}$ & $\begin{array}{c}\text { Sensitivity } \\
\text { Measurement Range }\end{array}$ & $\begin{array}{c}\text { Reference } \\
\text { Number }\end{array}$ \\
\hline 2003 & Suzuki et al. & Receptor & $\begin{array}{c}\text { Colorimetric reagents } \\
35^{\circ} \mathrm{C}\end{array}$ & $\begin{array}{c}0.13 \text { a.u./ppm } \\
0-1.0 \mathrm{ppm}\end{array}$ & {$[27]$} \\
\hline 2007 & Seo et al. & Receptor & $\begin{array}{l}\text { Mercaptophenol } \\
\text { No data }\end{array}$ & $\begin{array}{c}0.37 \mathrm{mV} / \mathrm{ppm} \\
0.027-2.7 \mathrm{ppm}\end{array}$ & [29] \\
\hline 2007 & Lee et al. & Transducer & $\begin{array}{c}\mathrm{NiO} \\
300^{\circ} \mathrm{C}\end{array}$ & $\begin{array}{c}0.33 \Omega / \mathrm{ppm} \\
0-30 \mathrm{ppm}\end{array}$ & [41] \\
\hline 2008 & Achmann et al. & Transducer & $\begin{array}{l}\text { Enzyme } \\
\text { No data }\end{array}$ & $\begin{array}{l}390 \mathrm{nA} / \mathrm{ppm} \\
0.5-15 \mathrm{ppm}\end{array}$ & [31] \\
\hline 2008 & Lv et al. & Transducer & $\begin{array}{l}\mathrm{SnO}_{2}-\mathrm{NiO} \\
300{ }^{\circ} \mathrm{C}\end{array}$ & $\begin{array}{c}0.53 \mathrm{ppm}^{-1}\left(\mathrm{R}_{\mathrm{a}} / \mathrm{R}_{\mathrm{g}}\right) \\
0.06-0.3 \mathrm{ppm}\end{array}$ & [45] \\
\hline 2008 & Bai et al. & Transducer & $\begin{array}{c}\mathrm{ZnO} \\
420^{\circ} \mathrm{C}\end{array}$ & $\begin{array}{c}10.6 \text { a.u./100ppm } \\
0-100 \mathrm{ppm}\end{array}$ & [34] \\
\hline 2008 & Wang et al. & Transducer & $\begin{array}{c}\mathrm{NiO}-\mathrm{Al}_{2} \mathrm{O}_{3} \\
300{ }^{\circ} \mathrm{C}\end{array}$ & $\begin{array}{l}70 \Omega / \mathrm{ppm} \\
0-15 \mathrm{ppm}\end{array}$ & [44] \\
\hline 2009 & Chu et al. & Transducer & $\begin{array}{c}\mathrm{ZnO} \\
210^{\circ} \mathrm{C}\end{array}$ & $\begin{array}{c}2.11 \mathrm{ppm}^{-1}\left(\mathrm{R}_{\mathrm{a}} / \mathrm{R}_{\mathrm{g}}\right) \\
1-10 \mathrm{ppm}\end{array}$ & [35] \\
\hline 2009 & Peng et al. & Transducer & $\begin{array}{c}\mathrm{ZnO} \\
25^{\circ} \mathrm{C}\end{array}$ & $\begin{array}{c}0.04 \mu \mathrm{A} / \mathrm{ppm} \\
0-50 \mathrm{ppm}\end{array}$ & [33] \\
\hline 2010 & Xie C et al. & Transducer & $\begin{array}{c}\mathrm{ZnO} \mathrm{MnO}_{2} \\
320^{\circ} \mathrm{C}\end{array}$ & $\begin{array}{l}1.02 \text { a.u./ppm } \\
10-300 \mathrm{ppm}\end{array}$ & [40] \\
\hline 2011 & Han et al. & Transducer & $\begin{array}{c}\mathrm{ZnO} \\
200{ }^{\circ} \mathrm{C}\end{array}$ & $\begin{array}{l}10 \text { a.u./ppm } \\
0-200 \mathrm{ppm}\end{array}$ & [36] \\
\hline 2011 & $\begin{array}{l}\text { Castro-Hurtado } \\
\text { et al. }\end{array}$ & Transducer & $\begin{array}{c}\mathrm{NiO} \\
340{ }^{\circ} \mathrm{C}\end{array}$ & $\begin{array}{c}2.53 \times 10^{3} \Omega / \mathrm{ppm} \\
5-20 \mathrm{ppm}\end{array}$ & [46] \\
\hline 2011 & Zhang et al. & Transducer & $\begin{array}{c}\mathrm{ZnO} \\
400{ }^{\circ} \mathrm{C}\end{array}$ & $\begin{array}{c}0.564 \mathrm{ppm}^{-1}\left(\mathrm{R}_{\mathrm{a}} / \mathrm{R}_{\mathrm{g}}\right) \\
1-1000 \mathrm{ppm}\end{array}$ & [37] \\
\hline 2011 & Descamps et al. & Transducer & $\begin{array}{c}\text { Fluoal-P } \\
\text { Room temperature }\end{array}$ & $\begin{array}{c}1.2 \times 10^{-5} \mathrm{Vs}^{-1} / \mathrm{ppb} \\
0-200 \mathrm{ppb}\end{array}$ & [28] \\
\hline 2012 & $\begin{array}{l}\text { Castro-Hurtado } \\
\text { et al. }\end{array}$ & Transducer & $\mathrm{SnO}_{2}$ & $10 \mathrm{M} \Omega / \mathrm{ppm}$ & [47] \\
\hline 2012 & Deng L et al. & Transducer & $\begin{array}{c}130{ }^{\circ} \mathrm{C} \\
\mathrm{WO}_{3} \\
\text { Room temperature }\end{array}$ & $\begin{array}{c}0.5-15 \mathrm{ppm} \\
3.7 \times 10^{-10}(\Omega \mathrm{s})^{-1} / \mathrm{ppm} \\
10-100 \mathrm{ppm}\end{array}$ & [39] \\
\hline 2012 & Deng B et al. & Receptor & $\begin{array}{c}\left(\mathrm{NH}_{3}\right)_{2} \mathrm{SO}_{4} \\
\text { No data }\end{array}$ & $\begin{array}{c}\text { No data } \\
0.48-96,000 \mathrm{mg} / \mathrm{m}^{3}\end{array}$ & [30] \\
\hline 2012 & $\mathrm{Xie} \mathrm{H}$ at al. & Transducer & $\begin{array}{l}\text { Carbon nanotube } \\
\text { Room temperature }\end{array}$ & $\begin{array}{c}0.4 \mathrm{ppm}^{-1}\left(\mathrm{R}_{\mathrm{a}} / \mathrm{R}_{\mathrm{g}}\right) \\
0-50 \mathrm{ppb}\end{array}$ & [48] \\
\hline
\end{tabular}




\section{Receptor-Based Formaldehyde Sensors}

In general, receptor functional sensors transform chemical information into some form of energy which may be measured by a transducer [25]. As discussed in the following, existing proposals for gaseous formaldehyde detection using sensing materials as receptors can be broadly categorized as either spectrometric, piezoresistive or colorimetric, respectively.

\subsection{Spectrometric Type}

In the spectrometric type of formaldehyde sensors, sensing molecules produce speedy color changes from colorless to colored under mild conditions, which was caused by the fact that an enaminone structure in the reagent reacted with formaldehyde to give a lutidine derivative. In 2003, Suzuki et al. [27] developed a portable sick house syndrome gas monitoring system based on colorimetric reagents for the highly selective and sensitive detection of formaldehyde. In general, spectrometric formaldehyde gas sensors utilize colorimetric formaldehyde-sensing molecules which possessed an enaminone structure (Figure 4(a)).

Figure 4. (a) Chemical structures of colorimetric reagents (KD-XA01 and KD-XA02) and their transformation into lutidine derivatives after reaction with formaldehyde. (b) (A) Schematic representation of the formaldehyde monitoring instrument and (B) the optical location of the LED and photodiode to detect the reflected light from the table in [27].

2
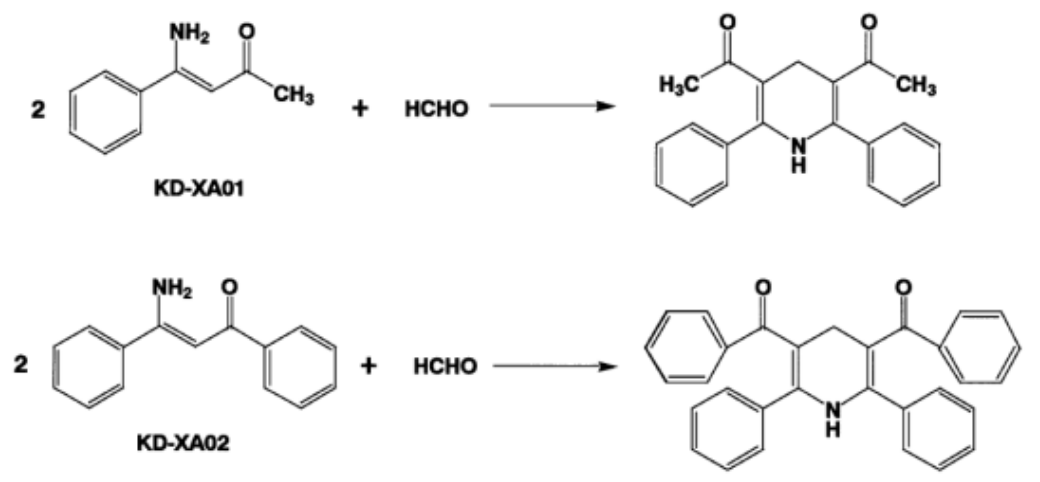

(a)

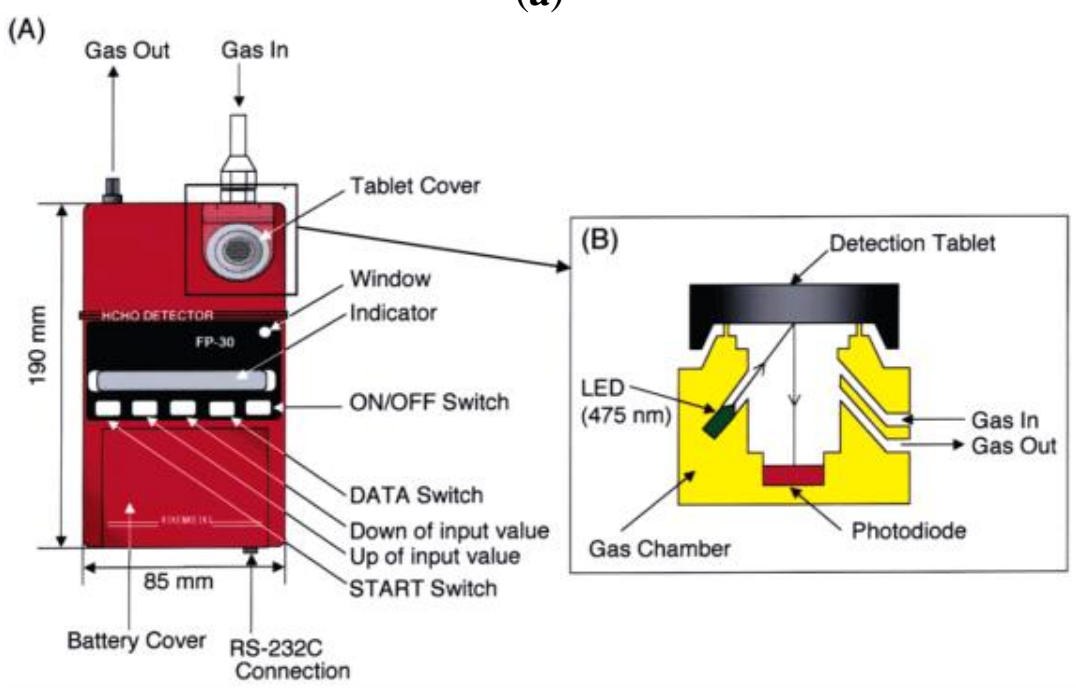

(b) 
The instrument (Figure 4(b)) detected the surface color change of the detection tablet from white to yellow, which was monitored as a function of the intensity of the reflected light illuminated by an LED $(475 \mathrm{~nm})$. The response was proportional to the formaldehyde concentration. Kawamura et al. [5] proposed a hand-held formaldehyde gas sensor comprising an LED light source (wavelength $540 \mathrm{~nm}$ ) and a circular filter impregnated with potassium hydroxide solution and $100 \mu \mathrm{L}$ of 4 -amino hydrazine5-mercapto-1,2,4-triazole (AHMT, see Figure 5(a)). When the filter was exposed to formaldehyde gas, the AHMT reagent reacted with the $\mathrm{HCHO}$ and resulted in a change in the color of the filter. The color change was then recorded by measuring the intensity of the light reflected from the surface of the filter using a photodiode. The results showed that a minimum detection limit of $0.04 \mathrm{ppm}$ HCHO was possible given a sampling time of $3 \mathrm{~min}$ or more (see Figure 5(b)).

Figure 5. (a) Schematic illustration of formaldehyde sensor based on photometer and reagent-filled filter. (b) Variation of sensor response with formaldehyde concentration given sampling times of 1,3 and $5 \min$ [5].

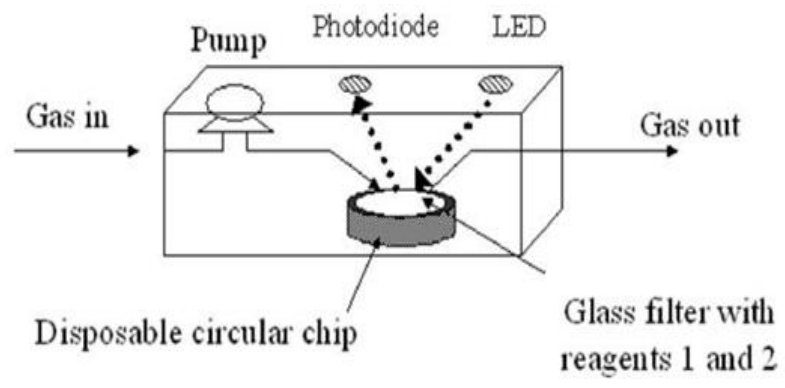

(a)

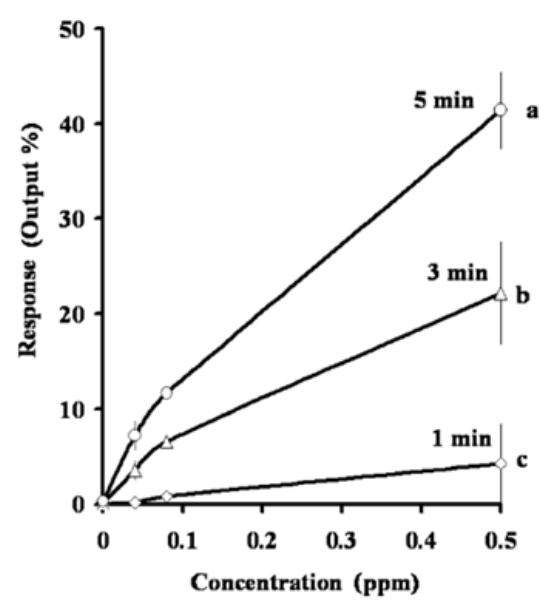

(b)

Descamps et al. [28] proposed a colorimetric device for measuring the concentration of gaseous formaldehyde incorporating a nanoporous film doped with Fluoral-P. When exposed to gaseous formaldehyde, the HCHO molecules reacted with the Fluoral-P reagent to form 3,5-diacetyl-1,4dihydrolutidine (DDL). The formaldehyde concentration was then determined by measuring the intensity of the fluorescence emission signal given the use of a LED illumination light source with a wavelength of $405 \mathrm{~nm}$ (see Figure 6(a)). In computing the formaldehyde concentration, the DDL concentration was formulated as:

$$
[\mathrm{DDL}]=a(1-\exp (-b t))
$$

where $a$ and $b$ include the reaction rate $k$, the initial concentration of Fluoral-P $[F]_{0}$, and the formaldehyde concentration [HCHO], i.e.,:

$$
\begin{gathered}
a \propto[F]_{0} \\
b=k[\mathrm{HCHO}]
\end{gathered}
$$

$[\mathrm{F}]_{0}$ was assumed to be constant throughout the experiments, and thus a $\mathrm{X} \mathrm{b}$ was proportional to the formaldehyde concentration (Equation (2)). The experimental results showed a relative scattering of 
$+20 \%$ for formaldehyde concentrations lower than $90 \mathrm{ppb}$ and a minimum detection limit of $30 \mathrm{ppb}$ (Figure 6(b)).

Figure 6. (a) Schematic illustration of formaldehyde sensor in which formaldehyde molecules react with Fluoral-P molecules to form DDL, which is then excited by LED with wavelength of $405 \mathrm{~nm}$; (b) Pulse-mode detection of HCHO in atmosphere with relative humidity of $50 \%$ with and without humidity filter, respectively [28].

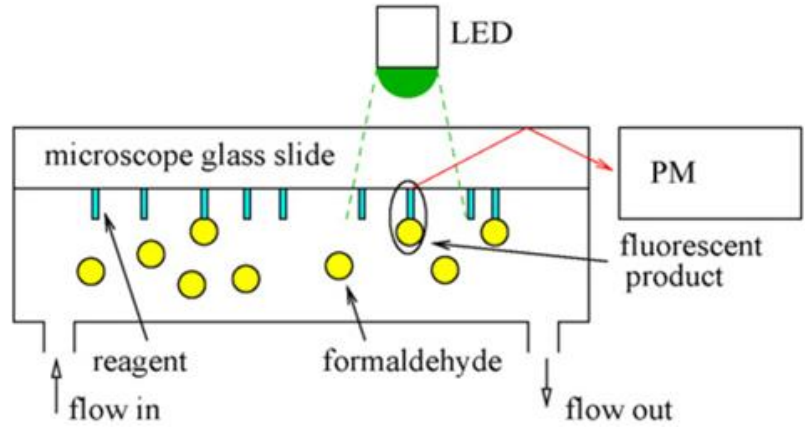

(a)
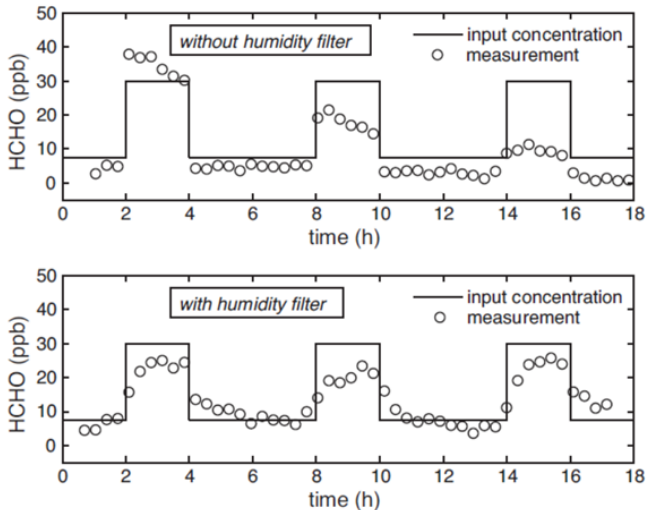

(b)

\subsection{Piezoresistive Type}

Piezoresistivity is a common sensing principle for micromachined sensors. Among all known piezoresistive materials, doped silicon, in particular, exhibits remarkable piezoresistive response characteristics. An electrical resistor may change its resistance when it experiences a strain and deformation. This effect provides an easy and direct energy/signal transduction mechanism between the mechanical and the electrical domains [22]. Seo et al. [29] proposed a gaseous formaldehyde sensor comprising a cantilever coated with a 3-mercaptophenol self-assembled monolayer (SAM, see Figure 7(a)).

Figure 7. (a) Schematic illustration of formaldehyde sensor comprising piezoresistive cantilever sensor platform. (b) Variation of output voltage and surface stress over time given increasing concentration of formaldehyde vapor [29].

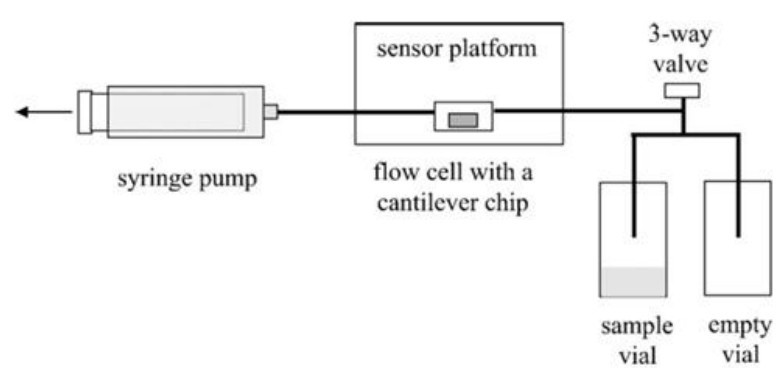

(a)

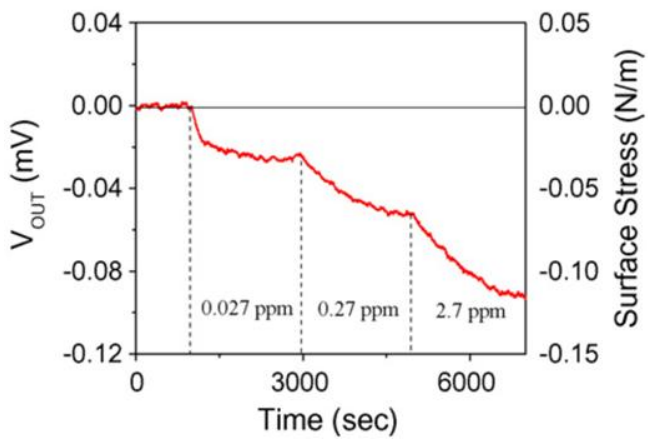

(b)

It was shown that when the cantilever was exposed to interferents such as benzene, toluene, p-xylene, water or ethanol, the cantilever deflection was in the opposite direction to that when the 
cantilever was exposed to formaldehyde. Thus, the selectivity of the sensor was confirmed. Furthermore, as shown in Figure 7(b), the minimum detection limit of the sensor was determined to be $0.027 \mathrm{ppm}$.

\subsection{Colorimetric Type}

The colorimetric type of sensors presents a decrease of reflectance intensity at a specific excitation wavelength. The color of the illuminated filter changes as the formaldehyde concentration changes. Wang et al. [13] proposed a colorimetric sensor for the detection of formaldehyde based on methyl yellow-impregnated electro-spinning/netting (ESN) Nylon 6 nano-fiber/nets (NFN, see Figure 8(a)).

Figure 8. (a) Schematic illustration showing preparation of methyl yellow-impregnated Nylon 6 colorimetric NFN membranes. (b) (i) and (ii) Variation of reflectance with wavelength as function of formaldehyde concentration, and (iii) color-differentiation map comprising converted RGB colors for various formaldehyde concentrations [13].

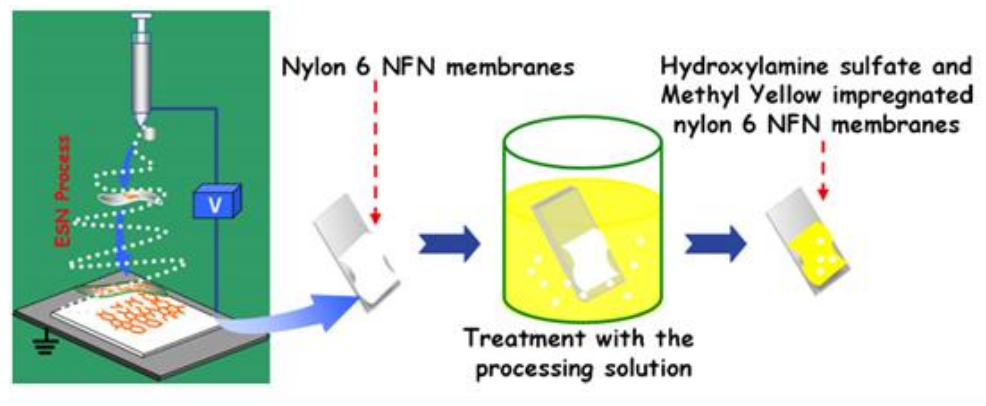

(a)
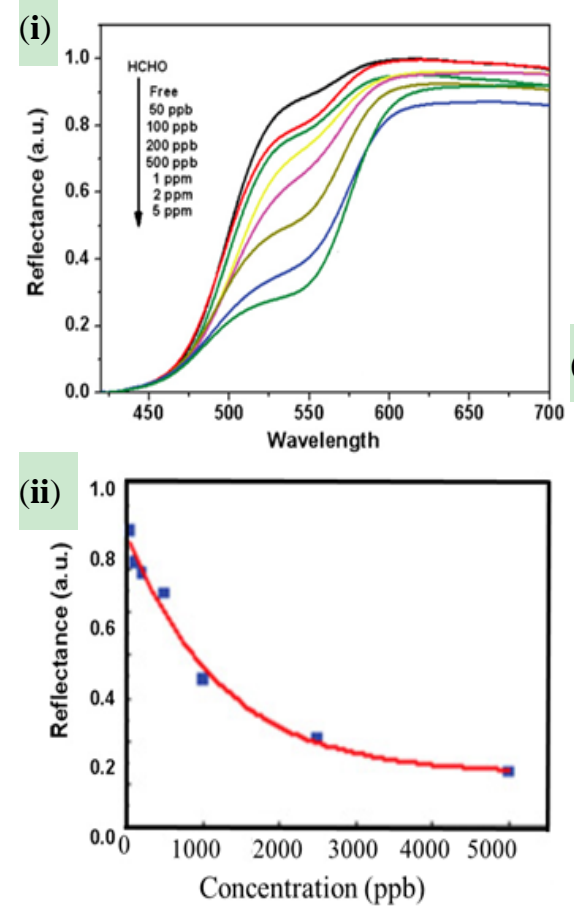

(iii)

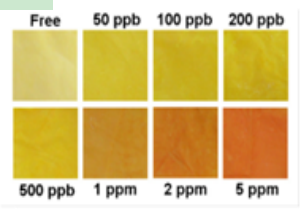

(b) 
When exposed to gaseous formaldehyde, the following reaction occurred:

$$
2 \mathrm{HCHO}+\left(\mathrm{NH}_{2} \mathrm{OH}\right)_{2} \cdot \mathrm{H}_{2} \mathrm{SO}_{4} \rightarrow 2 \mathrm{H}_{2} \mathrm{C}=\mathrm{NOH}+\mathrm{H}_{2} \mathrm{SO}_{4}+2 \mathrm{H}_{2} \mathrm{O}
$$

The sensor exhibited a significant decrease in the reflectance intensity at an excitation wavelength of $550 \mathrm{~nm}$. Moreover, it was shown that the color of the illuminated filter changed from yellow to red as the formaldehyde concentration was increased from $50 \mathrm{ppb}$ to $5 \mathrm{ppm}$ (see Figure 8(b)).

Deng et al. [30] presented a formaldehyde gas sensor based on an ammonium sulfate derivatization reagent and a capillary electrophoresis - electrochemical detection (CEED) system (see Figure 9). The reaction between the derivatization regent and formaldehyde was formulated as follows:

$$
4 \mathrm{NH}_{4}++6 \mathrm{HCHO} \stackrel{\leftrightarrow}{\rightarrow}\left(\mathrm{CH}_{2}\right)_{6} \mathrm{~N}_{4} \mathrm{H}^{+}+3 \mathrm{H}^{+}+6 \mathrm{H}_{2} \mathrm{O} .
$$

It was shown that the intensity of the detection signal varied linearly with the formaldehyde concentration over the range of $0.4 \mathrm{ppb}$ to $770 \mathrm{ppb}$. Moreover, the minimum detection limit was shown to be $0.12 \mathrm{ppb}$.

In general, formaldehyde gas sensors based on sensing material reagents have two major advantages compared to their previous counterparts (e.g., detection in solution state), namely (1) a lower detection limit, and (2) a more rapid response. However, they have a short lifetime since the sensing material is gradually consumed during the reaction process.

Figure 9. Gaseous formaldehyde detection system comprising pump (1), rotameter (2), reservoir bottle (3), solution exit (4), exit and solution entrance (5), ammonium sulfate solution (6), pipe (7) and piston with hole (8) [30].

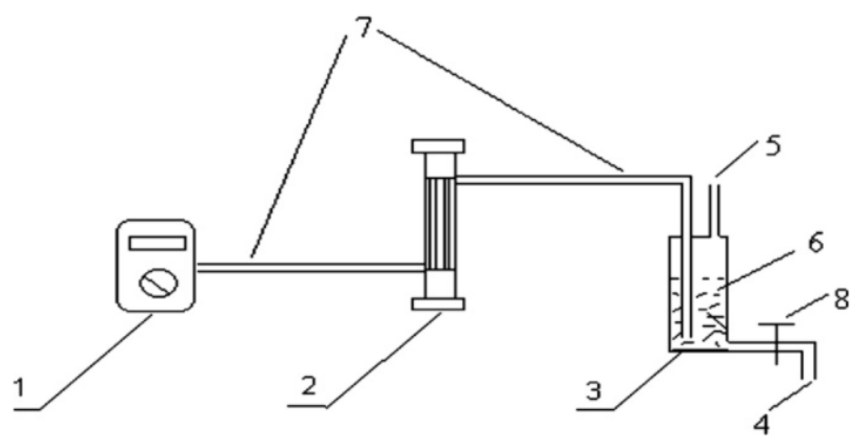

\section{Transducer-Based Formaldehyde Sensors}

Recently, many formaldehyde gas sensors incorporating micro- or nano-fabricated sensing materials as transducers have been proposed. The transducer functional sensors transform energy carrying the chemical information about the sample into a useful analytical signal [26]. Broadly speaking, these sensors can be categorized as either amperometric or conductimetric.

\subsection{Amperometric Type}

The detection of formaldehyde molecules presence in air on the basis of electric current or change in electric current is called an amperometric formaldehyde gas sensor. Achmann et al. [31] proposed an amperometric enzyme-based sensor-system for the detection of formaldehyde in air based on a native bacterial enzyme $\left(\mathrm{NAD}^{+}-\right)$and glutathione-independent formaldehyde dehydrogenase 
(see Figure 10(a)). The sensor device consisted of a 3-electrode configuration with disks of woven graphite gauze as working and counter electrode included in a plastic housing. Both electrodes were contacted with Pt-wire. The gas diffused into the liquid phase via a $15 \mathrm{~mm}$ diameter PTFE membrane. Gaseous formaldehyde samples were collected from the headspace above aqueous solutions of known concentration. The formaldehyde concentration in the gas phase above the solution was calculated according to the equation given by Dong et al. [32], as shown in Figure 11. It was shown that the sensitivity of the device was more than $90 \%$ and a $98.5 \%$ reproducibility of the sensor signal after $14 \mathrm{~h}$ at $4{ }^{\circ} \mathrm{C}$. However, the minimal detection limit was just $0.5 \mathrm{ppm}$ (see Figure $10(\mathrm{~b})$ ).

Figure 10. (a) Sensor for gaseous formaldehyde detection comprising multiple membranes and electrodes. (b) Characteristic response curve of sensor given different enzyme loads [31].

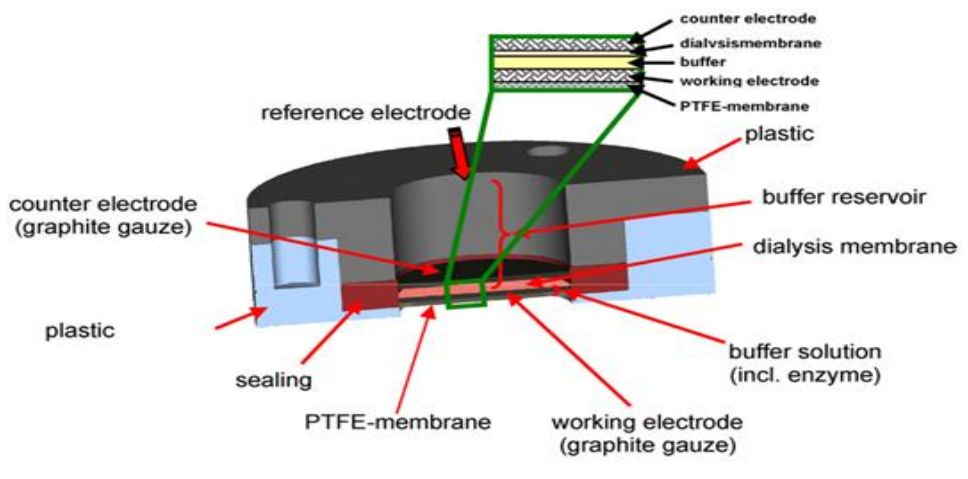

(a)

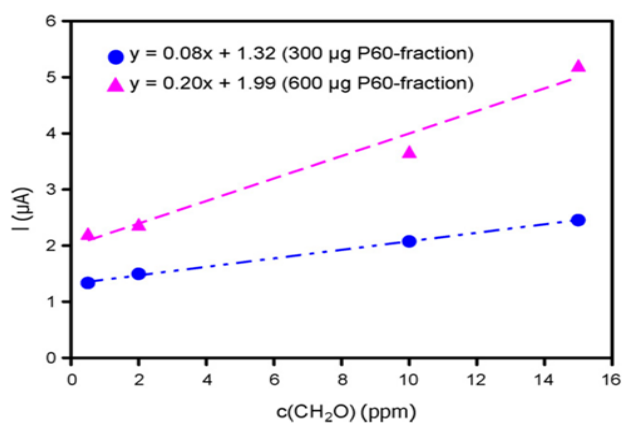

(b)

Figure 11. Formaldehyde concentration in the aqueous phase and the corresponding equilibrium gas phase concentrations at $20^{\circ} \mathrm{C}$ according to the equation given in [32].

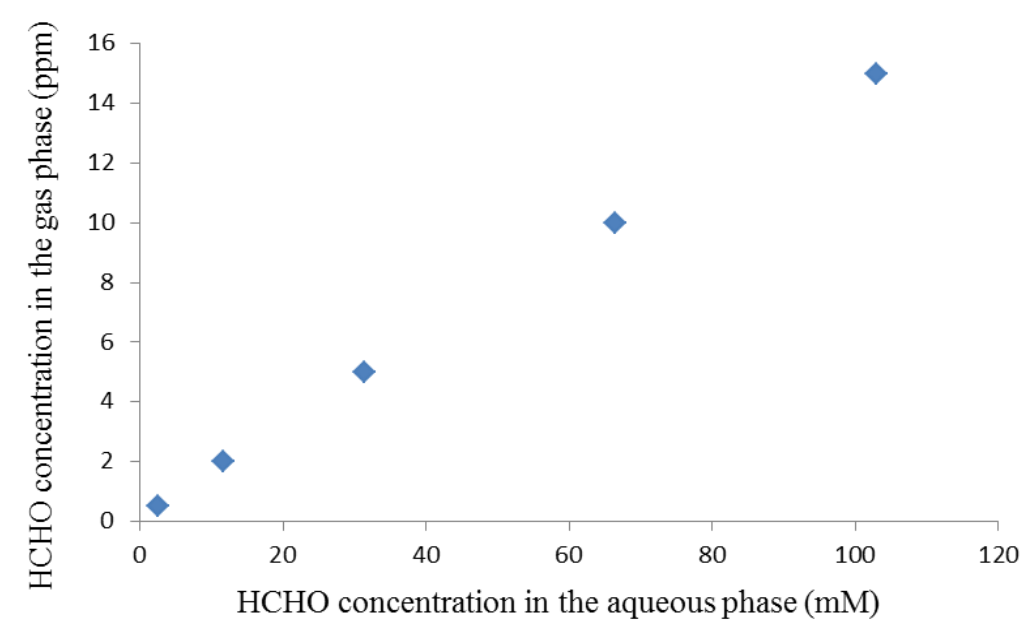

Peng et al. [33] developed a formaldehyde gas sensor comprising $\mathrm{ZnO}$ nanorods deposited on an ITO/glass substrate (see Figure 12(a)). The sensing characteristics of the proposed device were investigated both with and without ultraviolet (UV) irradiation. The UV-assisted formaldehyde sensing was demonstrated by detecting the photocurrent intensity change as the $\mathrm{ZnO}$ nanorods were exposed to formaldehyde. The enhancement of formaldehyde-response corresponded to the photocatalytic oxidation which was caused by the oxygen adsorbed on nanorods surface. The experimental results showed that the response of the nanorods to $110 \mathrm{ppm}$ of formaldehyde was around 120 times higher with UV light 
irradiation than without UV light irradiation. However, the minimal detection limit was just $1.8 \mathrm{ppm}$ (see Figure 12(b)).

Figure 12. (a) Formaldehyde sensor comprising nano-rods deposited on ITO/glass substrate; (b) Variation of photocurrent intensity with formaldehyde concentration [33].

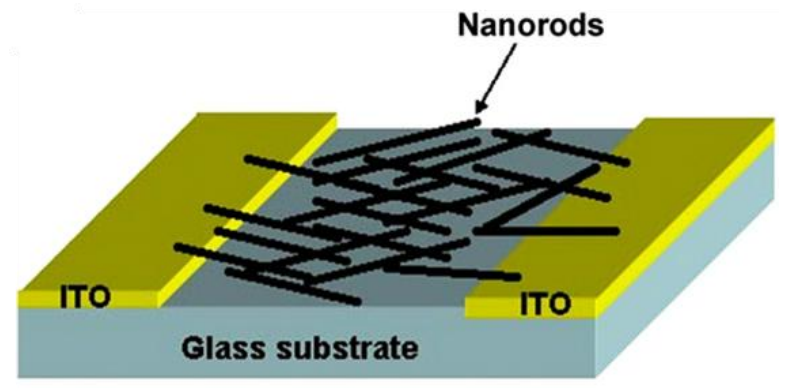

(a)

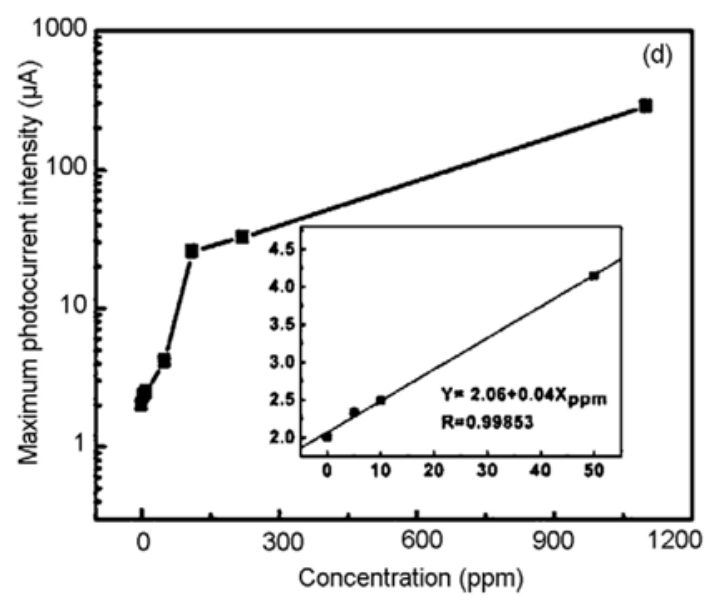

(b)

\subsection{Conductimetric Type}

The transduction mechanism of conductimetric formaldehyde gas sensors involves the changes in conductivity caused by the adsorption of formaldehyde gas. In the last decade, the detection of formaldehyde has been developed to provide formaldehyde exposure information on a real-time basis. Metal-oxide semiconductors (MOXs) are cheap and common catalysts used to induce the oxidation formaldehyde.

Figure 13. Schematic illustration of formaldehyde sensor comprising integrated micro-hotplate and IDEs [41].

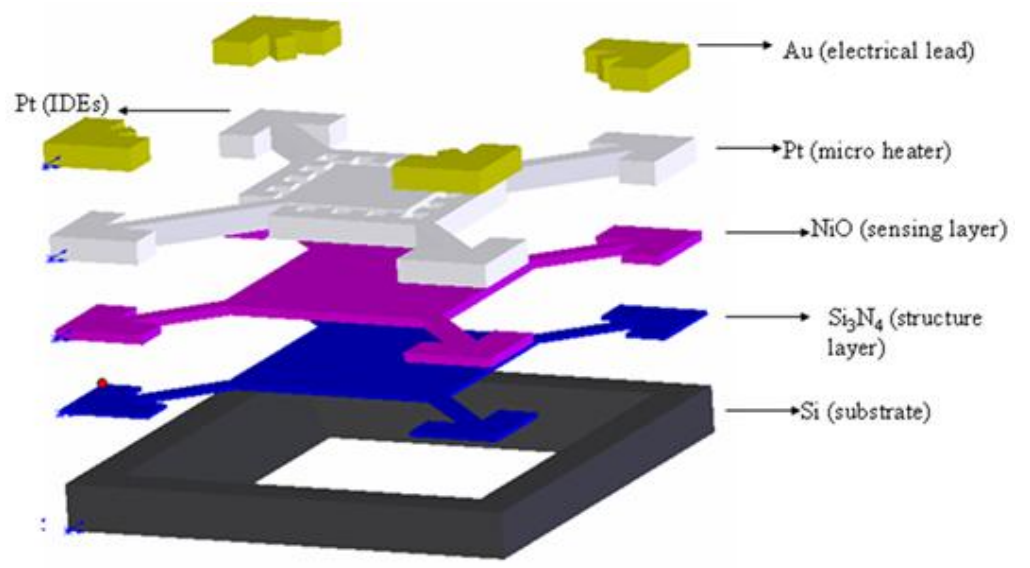

In MOX sensors, electron donors or acceptors in the gas phase adsorb onto the metal oxide. At high temperature $\left(>200^{\circ} \mathrm{C}\right)$, the adsorbed species can exchange electrons with the metal oxide. An electron donor increases the conductivity, while an acceptor molecule takes electrons and reduces its conductivity [33]. Commonly used materials include $\mathrm{ZnO}$ [34-38], $\mathrm{WO}_{3}$ [39], hybrid materials [40], 
$\mathrm{NiO}$ [41-44] and so on. Lee et al. [41] presented a gaseous formaldehyde sensor comprising a suspended silicon nitride microstructure with an integrated micro Pt heater, a thin-film $\mathrm{NiO}$ sensing layer, and Pt interdigitated electrodes (IDEs) (see Figure 13).

It was shown that in the presence of gaseous formaldehyde, an oxidation process occurred near the heated $\mathrm{NiO}$ sensing layer, which caused a change in the electrical conductivity of the $\mathrm{NiO}$ film and therefore changed the resistance between the interdigitated electrodes. It was further shown that the change in resistance varied linearly with the formaldehyde concentration in the range of $0-5 \mathrm{ppm}$. Thus, by measuring this change in resistance, the formaldehyde concentration could be inversely derived.

Dirksen et al. [42] examined all of the catalysts used for the oxidation of formaldehyde, and reported that the most active catalytic oxide appeared to be NiO. It was shown that the electrical conductivity of $\mathrm{NiO}$ depended significantly on the partial pressure of oxygen in the atmosphere. Moreover, it was shown that this phenomenon could be exploited to sense the concentration of gaseous formaldehyde by measuring the change in the electrical conductivity of the $\mathrm{NiO}$ oxide during the catalytic oxidation process. Wang et al. [44] proposed a MEMS-based formaldehyde gas sensor consisting of a thin-film NiO/ $/ \mathrm{Al}_{2} \mathrm{O}_{3}$ sensing layer deposited on a Pt-based hotplate (see Figure 14(a)).

Figure 14. (a) Schematic illustration of formaldehyde sensor comprising sensing layer deposited on micro-hotplate. (b) Variation of resistance with formaldehyde concentration [44].

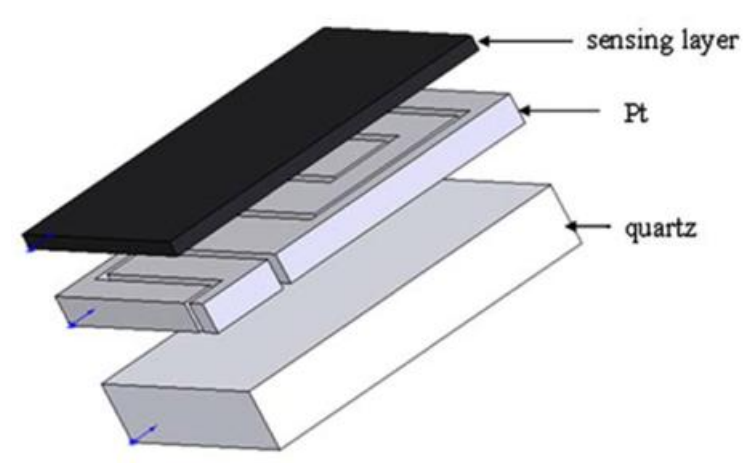

(a)

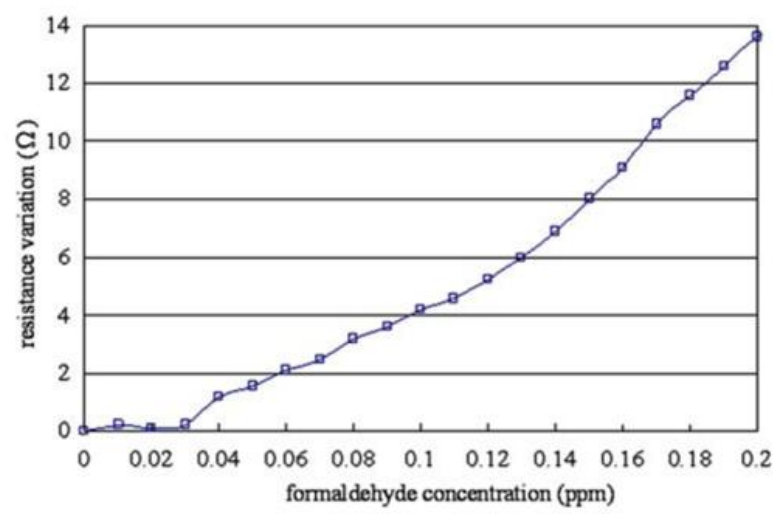

(b)

The experimental results showed that both the sensitivity of the sensor and the minimal detection limit could be improved by increasing the area of the sensing surface or reducing the thickness of the sensing layer. As shown in Figure 14(b), the minimal detection limit was found to be $40 \mathrm{ppb}$ given the use of a hybrid $\mathrm{NiO} / \mathrm{Al}_{2} \mathrm{O}_{3}$ sensing layer.

$\mathrm{Lv}$ et al. [45] developed a formaldehyde gas sensor incorporating a thin film of $\mathrm{SnO}_{2}-\mathrm{NiO}$ nanometer polycrystalline composite deposited on a micro-hotplate (MHP) (see Figure 15(a)). It was shown that the device was capable of detecting gaseous concentrations as low as $0.06 \mathrm{ppm}$ given a MHP working temperature of $300{ }^{\circ} \mathrm{C}$. Moreover, the device showed good selectivity in the presence of common interferents such as alcohol, toluene, $\alpha$-pinene and acetone (see Figure 15(b)). Gastro-Hurtado et al. [46] presented a $\mathrm{NiO}$ thin film formaldehyde gas sensor similar to that proposed by Lee et al. [41] and Wang et al. [44]. The same group also developed a gaseous formaldehyde sensor based on $\mathrm{SnO}_{2}$-nanowires grown by the catalytic oxidation of Sn-sputtered thin films [47]. The experimental results presented in 
Ref [47] showed that the addition of metal catalyst materials such as $\mathrm{Au}$ and $\mathrm{Pt}$ improved the sensor response and reduced the device operating temperature to $130{ }^{\circ} \mathrm{C}$.

Figure 15. (a) SEM image of micro-hotplate within dual-sensor detection chip. (b) Output response of sensor in presence of various compounds with different concentrations [45].

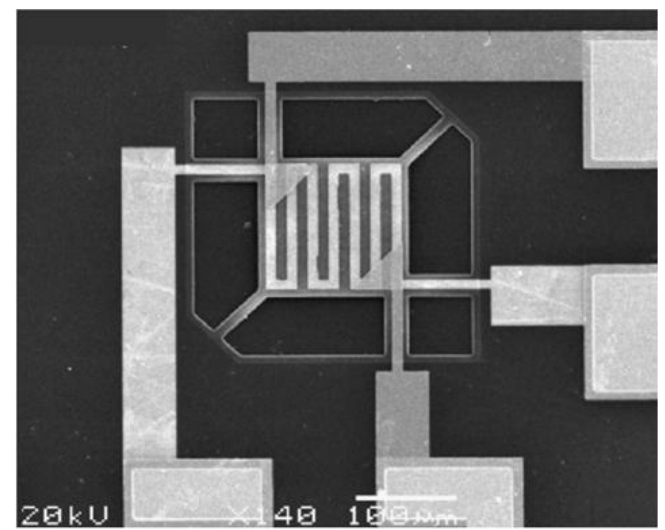

(a)

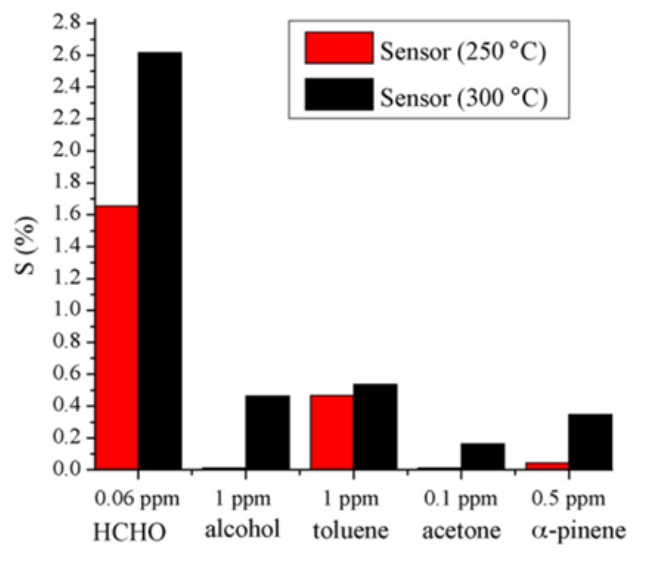

(b)

Recently, carbon nanotubes (CNTs) have been widely used as sensing materials to detect low concentrations of gases, such as nitrogen oxides, ammonia, hydrogen, carbon monoxide and some organic gases, due to their specific properties of nanometer hollow geometry, high specific surface area, high electron mobility, surface modification and functionalization [48]. Though a low concentration of formaldehyde (20 ppb) could be attained, the selectivity is still concerned in the development of gas sensors based on CNTs.

\section{Conclusions}

Technical advances in recent years now make possible the fabrication of sophisticated sensors for a diverse range of applications. Compared to their traditional macroscale counterparts, microscale sensors generally have greater sensitivity, lower cost, improved portability and more straightforward integration with IC circuit devices. This paper has presented a systematic review of the most significant formaldehyde gas sensors presented in the literature over the past 10 years or so. It has been shown that these sensors can be broadly categorized as "receptor-" or "transducer-" based formaldehyde sensors, respectively. The operational principles and sensing performance of each type of sensor have been discussed, and their relative advantages and disadvantages described where appropriate. Overall, the results presented in this review confirm the applicability of recently developed and advanced sensors for a diverse range of low-cost, high-performance gas sensing applications.

\section{Acknowledgments}

The authors would like to thank the financial support provided by the National Science Council in Taiwan (NSC 96-2221-E-212-037, NSC 99-2923-E-006-008-MY2, NSC 100-3113-E-020-001, NSC 100-2221-E-366-015, NSC100-2221-E-020-028 and NSC 101-2221-E-020-039). 


\section{References}

1. Korpan, Y.I.; Gonchar, M.V.; Sibirny, A.A.; Martelet, C.; El'skaya, A.V.; Gibson, T.D.; Soldatkin, A.P. Development of highly selective and stable potentiometric sensors for formaldehyde determination. Biosens. Bioelectron. 2000, 15, 77-83.

2. Kataky, R.; Bryce, M.R.; Goldenberg, L.; Hayes, S.; Nowak, A. A biosensor for monitoring formaldehyde using a new lipophilic tetrathiafulvalene- tetracyanoquinodimethane salt and a polyurethane membrane. Talanta 2002, 56, 451-458.

3. Kim, W.J.; Terada, N.; Nomura, T.; Takahashi, R.; Lee, S.D.; Park, J.H.; Konno, A. Effect on formaldehyde on the expression of adhesion molecule in nasal microvascular endothelial cells: The role of formaldehyde in the pathogenesis of sick building syndrome. Clin. Exp. Allergy 2002, 32, 287-295.

4. Hemple, A.J.; Kjaergaard, K.S.; Molhave, L.; Hundnell, H.K. Sensory eye irritation in humans exposed to mixture of volatile organic compounds. Arch. Environ. Health 1999, 54, 416-424.

5. Kawamura, K.; Kerman, K.; Fujihara, M.; Nagatani, N.; Hashiba, T.; Tamiya, E. Development of a novel hand-held formaldehyde gas sensor for the rapid detection of sick building syndrome. Sens. Actuators B Chem. 2005, 105, 495-501.

6. Que, Z.; Furuno, T.; Katoh, S.; Nishino, Y. Evaluation of three test methods in determination of formaldehyde emission from particleboard bonded with different mole ratio in the urea-formaldehyde resin. Build. Environ. 2007, 42, 1242-1249.

7. An, J.Y.; Kim, S.; Kim, H.J.; Seo, J. Emission behavior of formaldehyde and TVOC from engineered flooring in under heating and air circulation systems. Build. Environ. 2010, 45, 1826-1833.

8. Liu, J.; Wang, W.; Li, S.; Liu, M.; He, S. Advances in SAW gas sensors based on the condensate-adsorption effect. Sensors 2011, 11, 11871-11884.

9. Salem, M.Z.M.; Böhm, M.; Beránková, J.; Srba, J. Effect of some manufacturing variables on formaldehyde release from particleboard: Relationship between different test methods. Build. Environ. 2011, 46, 1946-1953.

10. Salem, M.Z.M.; Böhm, M.; Srba, J.; Beránková, J. Evaluation of formaldehyde emission from different types of wood-based panels and flooring materials using different standard test methods. Build. Environ. 2012, 49, 86-96.

11. He, Z.; Zhang, Y.; Wei, W. Formaldehyde and VOC emissions at different manufacturing stages of wood-based panels. Build. Environ. 2012, 47, 197-204.

12. Lu, N.; Pei, J.; Zhao, Y.; Qi, R.; Liu, J. Performance of a biological degradation method for indoor formaldehyde removal. Build. Environ. 2012, 57, 253-258.

13. Wang, X.; Si, Y.; Wang, J.; Ding, B.; Yu, J.; Al-Deyab, S.S. A facile and highly sensitive colorimetric sensor for the detection of formaldehyde based on electro-spinning/netting nano-fiber/nets. Sens. Actuators B Chem. 2012, 163, 186-193.

14. Air Quality Guidelines, 2nd ed.; WHO Regional Office for Europe: Copenhagen, Denmark, 2001.

15. Occupational Safety and Health Guideline for Formaldehyde Potential Human Carcinogen; U.S. Department of Health and Human Services: Washington, DC, USA, 1988.

16. Mohimann, G.R. Formaldehyde detection in air by laser induced fluorescence. Appl. Spectr. 1985, 39, 98-101. 
17. Dumas, T. Determination of formaldehyde in air by gas chromatography. J. Chromatogr. 1982, 247, 289-295.

18. Mann, B.; Grajeski, M.L. New chemiluminescent derivatizing agent for the analysis of aldehyde and ketones by high-performance liquid chromatography with peroxioxalate chemiluminescence. J. Chromatogr. 1987, 386, 149-158.

19. Lorrain, J.M.; Fortune, C.R.; Dellinger, B. Sampling and ion chromatographic determination of formaldehyde and acetaldehyde. Anal. Chem. 1981, 53, 1302-1305.

20. Septon, J.C.; Ku, J.C. Workplace air sampling and polarographic determination of formaldehyde. Am. Ind. Hyg. Assoc. J. 1982, 43, 845-852.

21. Hopkins, J.R.; Still, T.; Al-Haider, S.; Fisher, I.R.; Lewis, A.C.; Seakins, P.W. A simplified apparatus for ambient formaldehyde detection via GC-pHID. Atoms. Environ. 2003, 37, 2557-2565.

22. Flueckiger, J.; Ko, F.K.; Cheung, K.C. Microfabricated formaldehyde gas sensors. Sensors 2009, 9, 9196-9215.

23. Vianello, F.; Stefani, A.; Di Paolo, M.L.; Rigo, A.; Lui, A.; Margesin, B.; Zen, M.; Scarpa, M.; Soncini, G. Potentiometric detection of formaldehyde in air by an aldehyde dehydrogenase FET. Sens. Actuators B Chem. 1996, 37, 49-54.

24. Sritharathikhun, P.; Oshima, M.; Motomizu, S. On-line collection/concentration of trace amounts of formaldehyde in air with chromatomembrane cell and its sensitive determination by flow injection technique coupled with spectrophotometric and fluorometric detection. Talanta 2005, 67, 1014-1022.

25. Vianello, F.; Boscolo-Chio, R.; Signorini, S.; Rigo, A. On-line detection of atmospheric formaldehyde by a conductometric biosensor. Biosens. Bioelectron. 2007, 22, 920-925.

26. Hulanicki, A.; Glab, S.; Ingman, F. Chemical sensors definitions and classification. Pure Appl. Chem. 1991, 63, 1247-1250.

27. Suzuki, Y.; Nakano, N.; Suzuki, K. Portable sick house syndrome gas monitoring system based on novel colorimetric reagents for the highly selective and sensitive detection of formaldehyde. Environ. Sci. Technol. 2003, 37, 5695-5700.

28. Descamps, M.N.; Bordy, T.; Hue, J.; Mariano, S.; Nonglaton, G.; Schultz, E.; Tan-Thi, T.H. Vignoud-Despond, S. Real-time detection of formaldehyde by a sensor. Sens. Actuators B Chem. 2012, 170, 104-108.

29. Seo, H.; Jung, S.; Jeon, S. Detection of formaldehyde vapor using mercaptophenol-coated piezoresistive cantilevers. Sens. Actuators B Chem. 2007, 126, 522-526.

30. Deng, B.; Liu, Y.; Yin, H.; Ning, X.; Lu, H.; Ye, L.; Xu, Q. Determination of ultra-trace formaldehyde in air using ammonium sulfate as derivatization reagent and capillary electrophoresis coupled with on-line electrochemiluminescence detection. Talanta 2012, 91, 128-133.

31. Achmann, S.; Hermann, M.; Hilbrig, F.; Jérôme, V.; Hämmerle, M.; Freitag, R.; Moos, R. Direct detection of formaldehyde in air by a novel $\mathrm{NAD}^{+}$- and glutathione-independent formaldehyde dehydrogenase-based biosensor. Talanta 2008, 75, 786-791.

32. Dong, S.; Dasgupta, P.K. Solubility of gaseous formaldehyde in liquid water and generation of trace standard gaseous formaldehyde. Environ. Sci. Technol. 1986, 20, 637-640.

33. Peng, L.; Zhao, Q.; Wang, D.; Zhai, J.; Wang, P.; Pang, S.; Xie, T. Ultraviolet-assisted gas sensing: A potential formaldehyde detection approach at room temperature based on zinc oxide nanorads. Sens. Actuators B Chem. 2009, 136, 80-85. 
34. Bai, Z.; Xie, C.; Hu, M.; Zhang, S. Formaldehyde sensor based on Ni-doped tetrapod-shaped ZnO nanopowder induced by external magnetic field. Physica E 2008, 41, 235-239.

35. Chu, X.; Chen, T.; Zhang, W.; Zheng, B.; Shui, H. Investigation on formaldehyde gas sensor with $\mathrm{ZnO}$ thick film prepared through microwave heating method. Sens. Actuators B Chem. 2009, 142, 49-54.

36. Han, N.; Wu, X.; Zhang, D.; Shen, G.; Liu, H.; Chen, Y. CdO activated Sn-doped ZnO for highly sensitive, selective and stable formaldehyde sensor. Sens. Actuators B Chem. 2011, 152, 324-329.

37. Zhang, L.; Zhao, J.; Lu, H.; Gong, L.; Li, L.; Zheng, J.; Li, H.; Zhu, Z. High sensitive and selective formaldehyde sensors based on nanoparticle-assembled $\mathrm{ZnO}$ micro-octahedrons synthesized by homogeneous precipitation method. Sens. Actuators B Chem. 2011, 160, 364-370.

38. Zhang, L.; Zhao, J.; Zheng, J.; Li, L.; Zhu, Z. Shuttle-like ZnO nano/microrods: Facile synthesis, optical characterization and high formaldehyde sensing properties. Appl. Surf. Sci. 2011, 258, 711-718.

39. Deng, L.; Ding, X.; Zeng, D.; Tian, S.; Li, H.; Xie, C. Visible-light activate mesoporous $\mathrm{WO}_{3}$ sensors with enhanced formaldehyde-sensing property at room temperature. Sens. Actuators $B$ Chem. 2012, 163, 260-266.

40. Xie, C.; Xiao, L.; Hu, M.; Bai, Z.; Xia, X.; Zeng, D. Fabrication and formaldehyde gas-sensing property of $\mathrm{ZnO}-\mathrm{MnO}_{2}$ coplanar gas sensor arrays. Sens. Actuators B Chem. 2010, 145, 457-463.

41. Lee, C.Y.; Chiang, C.M.; Wang, Y.H.; Ma, R.H. A self-heating gas sensor with integrated NiO thin-film for formaldehyde detection. Sens. Actuators B Chem. 2007, 122, 503-510.

42. Dirksen, J.A.; Duval, K.; Ring, T.A. NiO thin-film formaldehyde gas sensors. Sens. Actuators $B$ Chem. 2001, 80, 106-115.

43. Hotovy, I.; Rehacek, V.; Siciliano, P.; Capone, S.; Spiess, L. Sensing characteristics of NiO thin films as $\mathrm{NO}_{2}$ gas sensor. Thin Solid Film. 2002, 418, 9-15.

44. Wang, Y.H.; Lee, C.Y.; Lin, C.H.; Fu, L.M. Enhanced sensing characteristics in MEMS-based formaldehyde gas sensors. Microsyst. Technol. 2008, 14, 995-1000.

45. Lv, P.; Tang, Z.A.; Yu, J.; Zhang, F.T.; Wei, G.F.; Huang, Z.X.; Hu, Y. Study on a micro-gas sensor with $\mathrm{SnO}_{2}-\mathrm{NiO}$ sensitive film for indoor formaldehyde detection. Sens. Actuators B Chem. 2008, 132, 74-80.

46. Castro-Hurtado, I.; Herrán, J.; Mandayo, G.G.; Castaño, E. Studies of influence of structural properties and thickness of $\mathrm{NiO}$ thin films on formaldehyde detection. Thin Solid Film. 2011, 520, 947-952.

47. Castro-Hurtado, I.; Herrán, J.; Mandayo, G.G.; Castaño, E. $\mathrm{SnO}_{2}$-nanowires grown by catalytic oxidation of tin sputtered thin films for formaldehyde detection. Thin Solid Film. 2011, 520, 4792-4796.

48. Xie, H.; Sheng, C.; Chen, X.; Wang, X.; Li, Z.; Zhou, J. Multi-wall carbon nanotube gas sensors modified with amino-group to detect low concentration of formaldehyde. Sens. Actuators B Chem. 2012, 168, 34-38.

(C) 2013 by the authors; licensee MDPI, Basel, Switzerland. This article is an open access article distributed under the terms and conditions of the Creative Commons Attribution license (http://creativecommons.org/licenses/by/3.0/). 